\title{
An Investigative Project in Chemical Engineering for Secondary School Mathematics Students
}

\author{
David C. Shallcross \\ Department of Chemical Engineering, University of Melbourne, Melbourne, \\ Victoria 3010 Australia
}

\begin{abstract}
Engineering faculties around the world must always work to ensure that they attract high standard students to their courses. Unfortunately prospective students have a poor appreciation of the engineering profession. They are often unaware of the diversity of challenges and opportunities that await them in an engineering career. A number of strategies exist to raise the profile of engineering within secondary schools. One activity involves targeting the students while still at school, with engineering academics either visiting the schools or playing host to the students on campus. An alternative to this is to present to mathematics teachers real engineering design problems that may be solved by the application of relatively simple mathematical concepts. This paper describes a challenge in chemical engineering design which can be answered in the class room by applying logic and a knowledge of the volumes of cylinders and rectangular prisms. The problem can be pitched to different year levels by selecting individual parts and can be undertaken by individuals or as a team exercise. Since originally being presented by the author in 1994, it has been developed into a book, co-written with four practicing mathematical teachers and published by the Mathematical Association of Victoria, the local association of mathematics teachers.
\end{abstract}

\section{Introduction}

The community in general has a very good appreciation of many of the professions vital to today's society. Through television and the wider media people generally know what doctors and lawyers, policemen and dentists do in their day to day activities. The same cannot be said for the engineering profession however. The popular image of the professional engineer is a man who wears a hard hat and builds bridges, tunnels and tall buildings. This inaccurate perception does not recognize the increasing number of women engineers nor the range of diverse engineering disciplines including chemical, civil, electrical, environmental, mechanical, petroleum and software engineering. If this is true for the general community it is certainly true for the secondary school community. Students and teachers alike usually do not have an appreciation of the diversity of challenges and opportunities that await them in an engineering career. 
While any secondary school student wishing to enter a university engineering program must have a high degree of competency in mathematics, most secondary school mathematics teachers do not have an appreciation for the engineering discipline. Whether they are teaching simple algebra or more advanced calculus, mathematics teachers at any year level are often confronted by students with questions such as "Why are we learning this?" and "What is this used for?". Often the teachers do not have the background to be able to answer these questions adequately.

While there is a clear need to raise the profile of the engineering profession in the secondary school community there are several ways to go about doing this. One strategy tried by many institutions and professional bodies has been to target secondary school students. By either sending academics out into the schools or by bringing school groups into the universities a limited number of potential engineering students become aware of the profession. The disadvantage with this strategy is that as the students advance through schools it is necessary to repeat these activities each year to a different cohort of students. A more efficient option is to work with teachers in programs which introduce them to engineering concepts in a way that is both interesting and of practical use in the class room.

When considering possible careers, secondary school students are often heavily influenced by their teachers. A teacher with a misconception of the engineering profession could, over their own career, encourage a generation of students to choose careers other than engineering. In some cases teachers have been known to actively discourage their brighter students from studying engineering. This is often particularly true at some single-sex girls schools in which teachers are not aware of the rising proportion of women working in the engineering profession.

Mathematics is the science that underpins all engineering. Good engineers must have superior mathematical skills and a sound grounding in analytical principles. Recognizing this in recent years the Faculty of Engineering at the University of Melbourne has begun working with local secondary school mathematics teachers to develop mathematics exercises which show how mathematics is used by engineers to solve real problems. Teachers and students alike appreciate and enjoy working with these real problems which demonstrate aspects of engineering design and problem-solving skills.

This paper describes a challenge in chemical engineering design that is based upon the design of a bulk liquid chemical storage facility or tank farm ${ }^{1}$. The project was originally presented to a pilot group of twelve mathematics teachers in 1994. After some early refinements in 1995 it was presented to some 200 teachers at a mathematics teachers conference in Melbourne ${ }^{2}$. Since 1995 the project has been used in secondary school class rooms around Victoria. In 1999 the author, working with four practicing mathematics teachers published a book which presents further problems based around the tank farm activity ${ }^{3}$. The book includes a selection of practical ideas for use in the class room. The activities include simple exercises that may be completed in minutes to week-long class projects. More recently the book has been used as the basis for profession development sessions for secondary school teachers in Australia, Indonesia, Malaysia and Vietnam. 


\section{Design Considerations for the Tank Farm Activity}

The following text introduces to the mathematics teachers of a properly-designed facility to store large volumes of potentially-hazardous chemicals.

The storage of dangerous chemicals is strictly regulated by government statutes. On the small laboratory scale in which the volume of liquids stored is measured in litres, these regulations can often be satisfied by storing the chemicals in glass flagons in special explosion-proof cupboards. Chemicals on this scale are easily stored, but still must be handled with a respect for their hazardous properties.

Consider now the chemical plant or refinery that processes $10,000 \mathrm{~m}^{3}$ of chemicals per day. Not only must the chemical plant site be able to store several weeks of supply of the feedstock required by the plant, but so too the site must also be capable of storing several weeks worth of production. Because of the hazardous nature of the chemicals care must be taken to ensure that they are stored safely. Any facility built to store chemicals must satisfy the relevant government regulations. In the State of Victoria the Dangerous Goods (Storage and Handling) Regulations 1989 must be complied with ${ }^{4}$. The Standards Association of Australia has also issued standards for the storage of dangerous chemicals: AS 1940-1993 The Storage and Handling of Flammable and Combustible Liquids ${ }^{5}$. Both these documents detail important features of a bulk liquid chemical storage facility that must be considered when such a facility is being designed and operated.

Bulk liquid chemicals are usually stored in cylindrical tanks that sit on the ground. The tanks usually sit vertically on a concrete base. The largest tanks (typically found at refineries) are usually short and squat. As an example a large tank may have a diameter of $45 \mathrm{~m}$ and a height of $21 \mathrm{~m}$. This gives a capacity of $33 \times 10^{3} \mathrm{~m}^{3}$.

The tanks must be surrounded by a raised barrier. The purpose of this barrier or dyke is to contain any liquid that might spill out of or leak from a tank. The barrier should also be able to contain any fire fighting water which may be poured or sprayed into the area when a tank or its contents are on fire. The barrier surrounding a tank or group of tanks is known as a bund, dyke or berm. We shall refer to it as a bund. The area enclosed by a bund is known as the spill collection compound, the containment area or the bunded area.

Figure 1 shows plan and elevation views of a typical spill collection compound that contains two equally-sized tanks. The two tanks are completed surrounded by the bund which is essentially a wall between $1.0 \mathrm{~m}$ and $1.5 \mathrm{~m}$ in height. Also shown in the diagram are the paved road and pipe track networks. A network of paved roads is needed in a bulk liquid chemical storage facility to permit free and unobstructed movement around the site. The pipe tracks contain the network of pipes used to move the liquids stored in the facility between the tanks and the loading and unloading points. In Figure 1 the pipe network is shown as being in a trench, passing beneath the roadways where necessary. It would be just as acceptable for the pipes to be housed in an elevated pipe rack above the ground and roadway. 


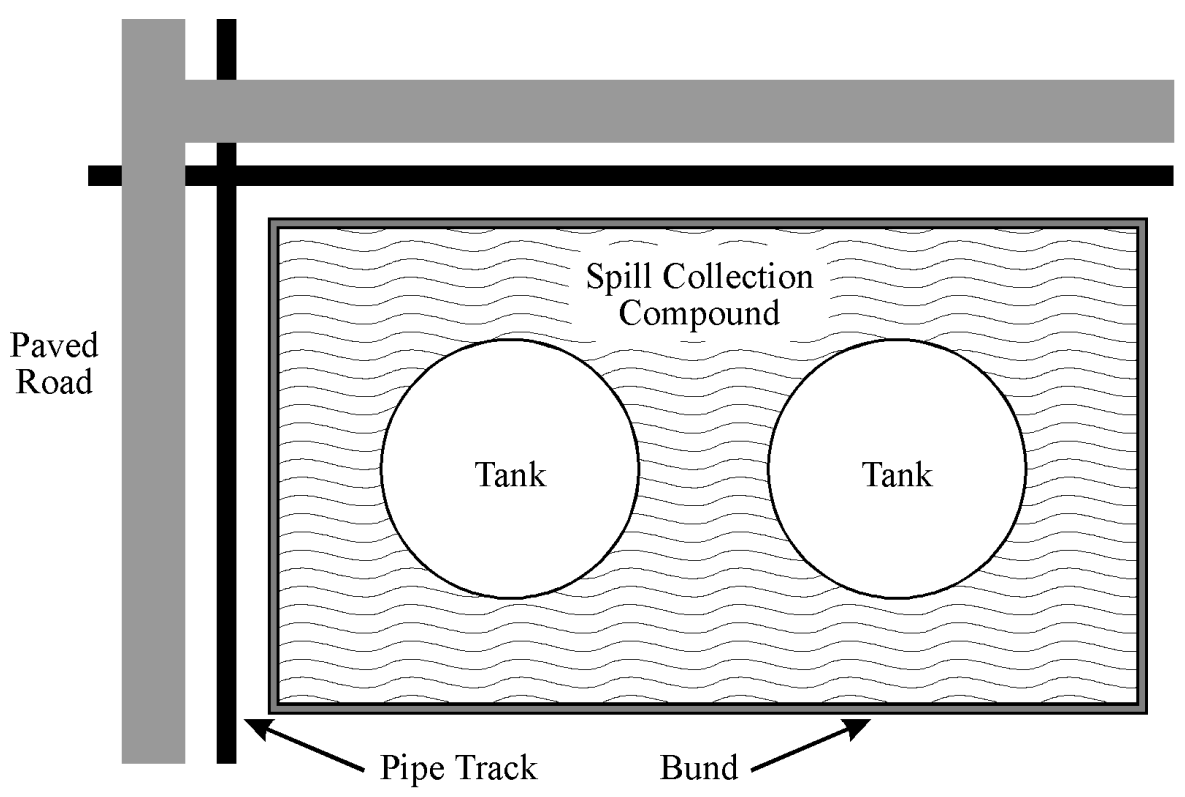

(a)

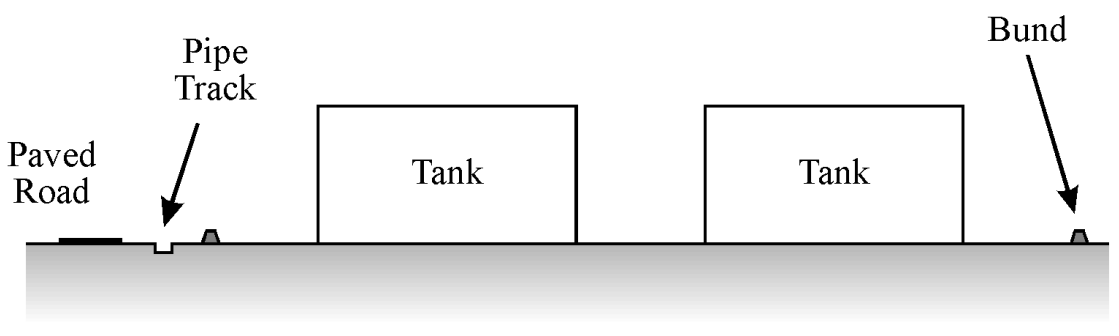

(b)

Figure 1: Views of a typical spill collection compound containing two tanks.

(a) plan view and (b) elevation.

After this introduction the major design requirements of the relevant government regulations and standards are introduced. These requirements are suitably simplified so that they are easier to work with in the class room without loosing any of the more significant design aspects. Some of these more important design considerations are listed below:

i) The ground within the spill collection compound must slope gently away from the tank to prevent accumulation of liquid around the base of the tank. If the liquid from a leak were to collect around the base of the tank, then in the event of a fire within the compound, the fire would be fuelled by this liquid and the tank would be put at extreme risk of catching fire. Any liquid spill must drain to a sump within the bunded area. This sump should be located well away from any tank. The drain from a sump should be designed so that any free liquid in the sump may be drained away at a rate at least equal to the rate at which firefighting water might be discharged into the compound. The drain should not discharge into another spill collection compound. 
ii) The bund must be no higher than $1.5 \mathrm{~m}$ above the compound floor to ensure adequate ventilation around the tanks and to allow rapid egress from the compound in an emergency.

iii) The bund must be constructed of material which is impervious to, and compatible with, the dangerous chemicals stored within the compound. A bund of concrete would not be acceptable if were known that the chemicals stored within the tanks of the spill collection compound were susceptible to attack by the chemical.

iv) The perimeter of the spill compound must be located a sufficient distance from all tanks within the compound to prevent a leak from the surface of the tank spilling over the bund outside the compound. The minimum distance between a tank and the bund wall is one half the height of the tank above the top of the bund wall.

v) The bund must be designed to withstand the hydrostatic head when the compound is full of liquid. The bund usually has a trapezoidal cross-section with the flat section at the top being wider than the base of the bund.

vi) The bund wall must have a flat section at the top not less than $600 \mathrm{~mm}$ wide. Following the 1991 fire at the Coode Island facility the Melbourne Metropolitan Fire Brigade submitted at the Coronial Inquest that the tops of the bunds should have a flat section not less than $2 \mathrm{~m}$ wide. This would allow two fire fighters carrying equipment to pass. This suggestion has not yet been adopted.

vii) Incompatible chemicals may not be stored within the same bunded area. Two chemicals would be incompatible if they were to explosively react in contact with one another.

Obviously it would be highly undesirably for two such chemicals to mix on the floor of the spill collection compound if the tanks storing them in the same compound were to both leak.

viii) The compound may not contain any equipment other than the tanks themselves and the pipes that service them. Pumps are not permitted within the spill collection compound. The compound must be kept clean and free of all vegetation.

ix) A fixed fire protection system must be installed outside the compound. This system must be designed so that all tanks within the compound may be covered in the event of a fire.

x) The spill collection compound enclosed by the bund must have a net capacity at least equivalent to the capacity of the largest tank in the compound plus ten percent of the capacity of the second largest tank plus a volume equal to the output of the compounds firefighting sprinkler system over a period of twenty minutes.

xi) There is a minimum safe separation distance between adjacent tanks in the same compound which must be satisfied. The tanks must be far apart so that if the contents of one tank were to catch fire, then the risk of the fire spreading to the adjacent tanks would be minimal. The Australian Standards specifies that the minimum distance between any two tanks in the same collection area depends upon the diameters of the two tanks: 
a) If neither tank exceeds $6 \mathrm{~m}$ in diameter, the distance between them shall be not less than either one-third of the diameter of the larger tank or $1 \mathrm{~m}$, whichever is the greater.

b) If one of the tanks is more than $6 \mathrm{~m}$ but neither is more than $20 \mathrm{~m}$ in diameter, the distance between them shall be not less than one-half of the diameter of the larger tank.

c) If one of the tanks is $20 \mathrm{~m}$ or more in diameter, the distance between it and any other tank shall not be less than $15 \mathrm{~m}$.

xii) The spill collection compound must be separated from protected works by at least $5 \mathrm{~m}$. Protected works include any building or open area in which people are accustomed to assemble or in which people are employed. Included in this definition are dwellings, schools, hospitals, places of worship, theatres, offices, factories, shops, stores and warehouses. A ship lying at a permanent berthing facility is also deemed to be a protected works.

xiii) Spill collections compounds should also be far enough apart so that emergency services may rapidly be deployed as necessary.

xiv) Australian Standard 1940-1993 requires that the net capacity of a spill collection compound should be greater than the capacity of the largest tank. However, the Dangerous Goods (Storage and Handling) Regulations 1989 issued by the Victorian Government require that the area enclosed by the bund has a net capacity greater than the largest tank in the compound plus ten percent of the capacity of the second largest tank plus a volume equal to the output of the fire fighting sprinkler system over a period of 20 minutes. The more stringent requirements of the Dangerous Goods Regulations are adopted in our design of the compound.

xv) Except for a compound containing a single tank, the total aggregate volume of flammable liquids that may be stored within a spill collection compound must be less than $60000 \mathrm{~m}^{3}$ where any tank in the compound has a fixed roof, of less than $120000 \mathrm{~m}^{3}$ where all the tanks are fitted with floating-roofs. This difference arises because floating roof tanks are inherently safer than fixed roof tanks.

xvi) Where the aggregate capacity of the tanks in any compound exceeds $10000 \mathrm{~m}^{3}$, intermediate bunds must be used to divide the compound so that the aggregate volume of the tanks in any subdivision is less than $10000 \mathrm{~m}^{3}$. The only exception to this is when a subdivision contains a single tank with a capacity of more than $10000 \mathrm{~m}^{3}$. The intermediate bunds must have a height above the compound floor of at least half the height of the main bunds or $600 \mathrm{~mm}$, whichever is the lesser.

The design figures given above are taken from the appropriate government regulations and Australian Standards and are applicable to tank farms throughout Melbourne and the State of Victoria. While other locations around the world may have different government regulations and national standards the basic concepts of consideration for safe engineering design will still exist. 


\section{A Worked Example of a Single Tank Storage Facility}

To illustrate the use of simple mathematics to design a suitable storage facility the case of a single tank may be presented to the teachers. As our first example we shall design a facility to store $500 \mathrm{~m}^{3}$ of acetone in a single tank. The acetone will be stored in a vertical, cylindrical tank having a circular cross-section. In designing the facility we will calculate the size of the tank and the dimensions of the associated spill collection compound.

As a first step in our design calculations we list the assumptions we will make in order to simplify the calculations.

i) While the ground should slope away from each tank we will assume the floor of the compound is flat. This keeps the complexity of the calculations at a level suitable for the class room.

ii) The bund walls will be assumed to be vertical. The actual cross-section of a bund is trapezoidal. Again, this assumption maintains the complexity of the calculations at a suitable level without significantly affecting the calculated results.

iii) The base of each tank will be assumed to be level with the floor of the spill collection compound.

iv) The thickness of the tank wall is negligible.

v) The terrain upon which the compound is to be built is assumed to be flat.

The volume of a circular cylinder is given by the equation:

$$
\mathrm{V}=\frac{\pi \mathrm{d}^{2} \mathrm{~h}}{4}
$$

where $\mathrm{V}$ is the volume, $\mathrm{d}$ is the diameter and $\mathrm{h}$ is the height. Since the volume of the tank is fixed at $500 \mathrm{~m}^{3}$ we are free to specify a value for either the diameter of the tank or its height. Once one of these values is specified then the other may be calculated. Re-arranging equation (1) we can obtain an expression for the diameter as a function of the tank height:

$$
\mathrm{d}=\sqrt{\frac{4 \mathrm{~V}}{\pi \mathrm{h}}}=\sqrt{\frac{4 \times 500 \mathrm{~m}^{3}}{\pi \mathrm{h}}}
$$

From this we see that as the height increases, the diameter decreases. In this example we will assume that the diameter of the tank is approximately equal to its height. If we set the height and diameter to be equal then equation (1) becomes :

$$
\mathrm{V}=\frac{\pi \mathrm{d}^{3}}{4}
$$

and so,

$$
\mathrm{d}=\sqrt[3]{\frac{4 \mathrm{~V}}{\pi}}=\sqrt[3]{\frac{4 \times 500 \mathrm{~m}^{2}}{\pi}}=8.60 \mathrm{~m}
$$

Our tank will therefore have a diameter of $8.60 \mathrm{~m}$ and a height of $8.60 \mathrm{~m}$. Now we must consider the design for the spill collection compound. 
The Victorian Government Regulations specify that the area enclosed by the bund has a net capacity greater than the largest tank in the compound plus ten percent of the capacity of the second largest tank plus a volume equal to the output of the fire fighting sprinkler system over a period of 20 minutes. Since our compound contains one tank only, the specification may be represented as:

$$
\left(\begin{array}{c}
\text { Minimum } \\
\text { Volume }
\end{array}\right)=\left(\begin{array}{c}
\text { Volume of } \\
\text { Tank }
\end{array}\right)+\left(\begin{array}{c}
20 \text { Minute } \\
\text { Supply of Fire } \\
\text { Fighting Water }
\end{array}\right)
$$

For a single tank installation we shall assume that the maximum flow rate of fire water into the compound is $1.0 \mathrm{~m}^{3} / \mathrm{min}$. Thus, the maximum volume of fire fighting water able to be delivered into the compound in 20 minutes is $20.0 \mathrm{~m}^{3} / \mathrm{min}$.

Applying equation (3.5) we find that

$$
\left(\begin{array}{c}
\text { Minimum } \\
\text { Volume }
\end{array}\right)=500+20.0=520 \mathrm{~m}^{3}
$$

Now we must calculate the floor area of the spill collection compound. The Australian Standards specify that a bund wall be no higher than $1.5 \mathrm{~m}$ above the floor of the compound. We shall assume that the bund is $1.5 \mathrm{~m}$, but that the liquid within the spill collection compound will rise no higher than an average depth of $1.40 \mathrm{~m}$. This allows a safety margin of $10 \mathrm{~cm}$. So, the minimum floor area of the spill collection compound may be calculated as:

$$
\text { Area }=\frac{\text { Volume }}{\text { Depth }}=\frac{520 \mathrm{~m}^{3}}{1.4 \mathrm{~m}}=371.4 \mathrm{~m}^{2}
$$

This calculation assumes that the interior walls of the bund are vertical and that the floor is horizontal and flat.

The single tank will sit in the centre of a square spill collection compound as shown in Figure 2. We will let the symbol L denote the interior length of one side of the compound. The floor area of the compound available to contain a spill is the shaded area indicated in Figure 2. It is given by the equation :

$$
\text { Area }=L^{2}-\frac{\pi d^{2}}{4}
$$

where the second term on the right-hand side accounts for the area taken up by the base of the tank. Re-arranging and substituting in the appropriate values for the area and tank diameter yields: 


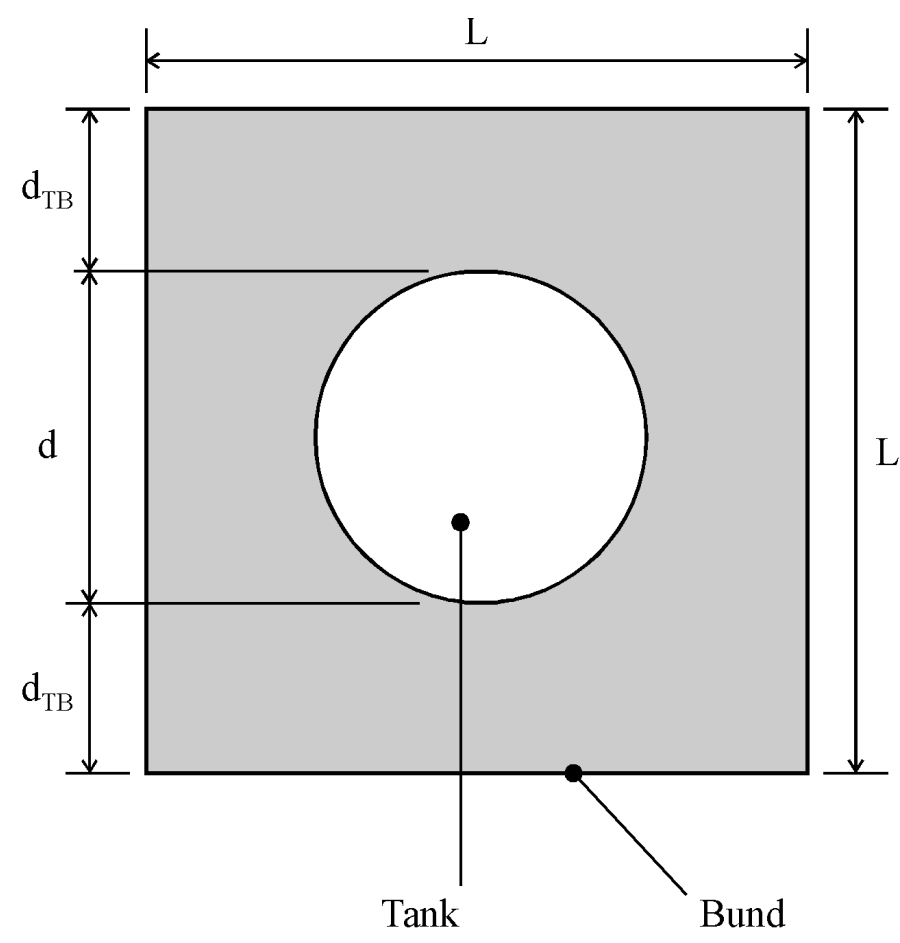

Figure 2 : The spill collection compound with a single tank.

$$
\mathrm{L}=\sqrt{\text { Area }+\frac{\pi \mathrm{d}^{2}}{4}}=\sqrt{371.4+\frac{\pi(8.60)^{2}}{4}}=20.72 \mathrm{~m}
$$

This tells us that a square spill collection compound with an edge length of $20.71 \mathrm{~m}$ have a capacity sufficient to satisfy the requirements of the Government Regulations. We shall round up this value and use an edge length of $20.8 \mathrm{~m}$. If the tank is located in the centre of the square compound then the distance between the tank and each of the bund walls may be calculated. As may be seen from Figure 2 we may write:

$$
\mathrm{L}=\mathrm{d}_{\mathrm{TB}}+\mathrm{d}+\mathrm{d}_{\mathrm{TB}}
$$

Re-arranging and substituting in the values for $\mathrm{L}$ and $\mathrm{d}$ we find:

$$
\mathrm{d}_{\mathrm{TB}}=\frac{\mathrm{L}-\mathrm{d}}{2}=\frac{20.8-8.6}{2}=6.1 \mathrm{~m}
$$

The Australian Standards specify that the minimum distance, $\mathrm{d}_{\mathrm{TB}}$, between a tank and the inside bund wall is to be at least one half the height of the tank above the level of the top of the bund wall. Since the top of the bund is $1.5 \mathrm{~m}$ above the floor of the compound and the height of the tank is $8.6 \mathrm{~m}$ we find that : 


$$
\mathrm{d}_{\text {тв }} \geq \frac{8.6-1.5}{2}=3.55 \mathrm{~m}
$$

Since the distance between the tank and the bund wall in our design is greater than $3.55 \mathrm{~m}$, our design satisfies the spacing requirements of the Standards.

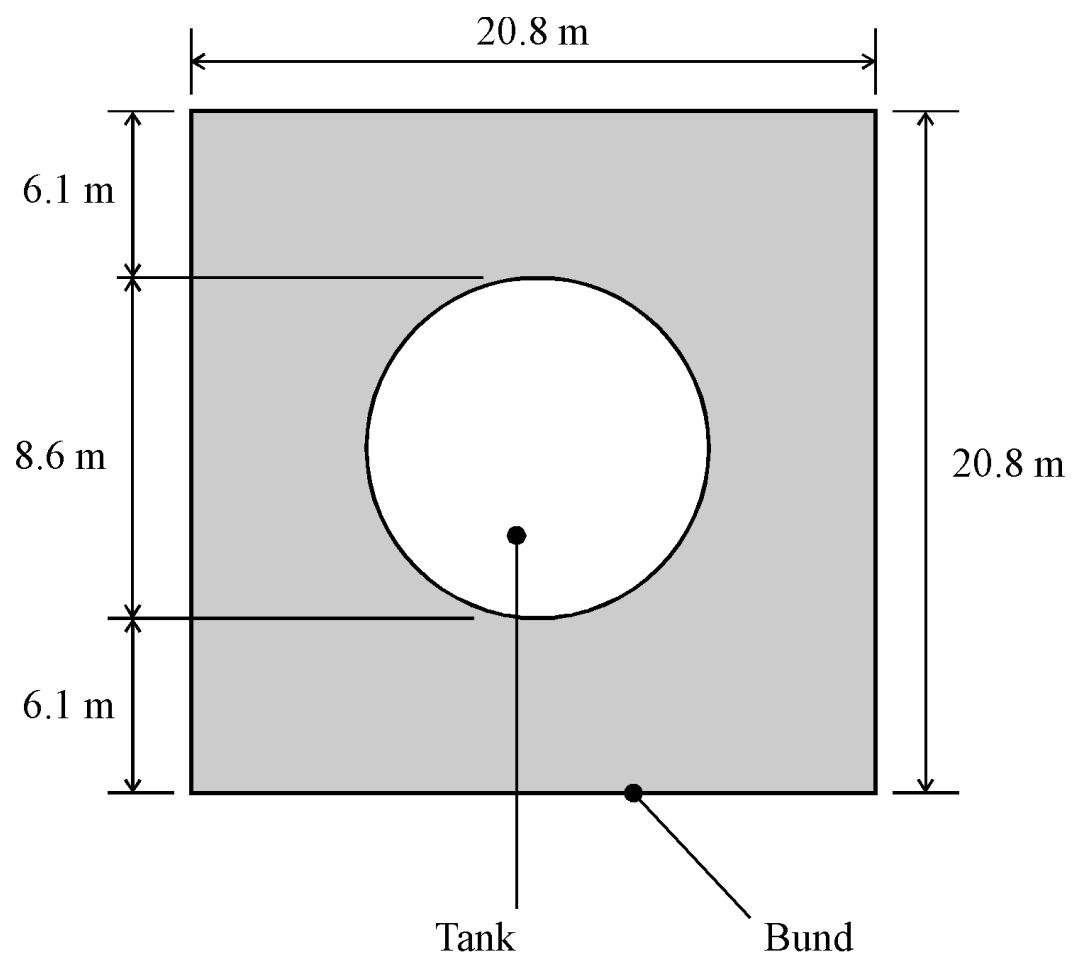

Figure 3 : The spill collection compound with dimensions.

\section{Other Mathematical Exercises Arising from the Tank Farm Activity}

Once the teachers have been provided with the above background material a range of other exercises may be set. These activities, presented in the book ${ }^{3}$, include topics such as area, rates and volumes, probability, circular functions and conic sections. Examples of some of these exercises are presented below.

1) One of the tanks at a spill collection compound is found to have just started leaking. The initial volume of oil in the tank is $1100 \mathrm{~m}^{3}$. Eight hours later the site engineer finds that only $200 \mathrm{~m}^{3}$ remains. If the volume, $\mathrm{V}$, remaining in the tank after time, $\mathrm{t}$, can be approximated by:

$$
\mathrm{V}=\mathrm{V}_{\mathrm{o}} \mathrm{e}^{-\mathrm{kt}}
$$

where $\mathrm{V}_{\mathrm{o}}$ and $\mathrm{K}$ are constants, $\mathrm{V}$ is the volume in $\mathrm{m}^{3}$ and $\mathrm{t}$ is the time in hours.

a) Find the values for $\mathrm{V}_{\mathrm{o}}$ and $\mathrm{k}$. 
b) If the leak was discovered at $11 \mathrm{pm}$, how much oil, correct to two decimal places, would remain in the tank by 8 am the next morning ?

c) At what time will the tank be half empty.

2) Liquid chemical storage tanks actually sit on a surface that slopes away from the tank (this is so that any spillage will flow way from the tank). This surface can be modeled by a truncated cone. The diameter of the base of a truncated cone is $18 \mathrm{~m}$ and the diameter of the top is $10 \mathrm{~m}$. The angle the slant edge makes with the horizontal is $20^{\circ}$.

a) Find the height (to the nearest centimetre) of a cone with a diameter of $18 \mathrm{~m}$ and a slant angle of $20^{\circ}$.

b) Find the height (to the nearest centimetre) of a cone with a diameter of $10 \mathrm{~m}$ and a slant angle of $10^{\circ}$.

c) Now find the height (to the nearest centimetre) of the truncated cone.

d) How many cubic metres of concrete, correct to two decimal places, are required to make the truncated cone?

\section{Concluding Remarks}

The tank farm design project has been used in secondary schools in and around Melbourne for nearly seven years. Its development is the most advanced of a number of engineering-themed activities developed by the author in the last five years. Other activities include the mathematics and engineering behind some aspects of milk production ${ }^{6}$, the application of graphs in petroleum engineering $^{7}$ and the use of spreadsheets for a simple process control problem ${ }^{8}$. This project has been successfully used as a basis for a series of professional development sessions run for secondary school mathematics teachers in four countries.

It is not possible to quantify the increase in interest in engineering amongst secondary school students as a result of the use of the tank farm and other similar activities in class room. Anecdotal evidence suggests that however that they have been useful in demonstrating that engineering is broader than just civil engineering.

The author hopes that readers will be encouraged to develop this and other activities further for use in class rooms in their home locations.

\section{Bibliography}

1. Shallcross D.C., 1997, 'An Investigative Project in Chemical Engineering for School Students', Chemical Engineering Education, 31(2), pp 138-141

2. Shallcross D.C., 1995, 'Investigative Project in Engineering : Designing a New Coode Island', Proceedings of the Mathematics Association Victoria 32nd Annual Conference, Melbourne, December 1995

3. Shallcross D.C., Dell'Oro D., Lamson D., Schaffner M., Vincent J., 1999, 'Designing a Bulk Liquid Chemical Storage Facility', Mathematical Association of Victoria, Melbourne, 1999

4. State of Victoria, 1991, 'Dangerous Goods (Storage and Handling) Regulations 1989 - Dangerous Goods Act 1985', Printing and Publishing Services Victoria, Melbourne, 1991 
5. Australian Standards, 1988, 'AS 1940-1988 The Storage and Handling of Flammable and Combustible Liquids', Standards Association of Australia, Canberra, 1988

6. Shallcross D.C., 2000, 'A Sample Applications Task For Mathematical Methods Unit 3 Coursework Assessment', Vinculum, 37(3), pp4-5

7. Shallcross D.C., 2000, 'Investigative project in petroleum engineering - the mathematics of drilling an oil well', Proceedings of the Mathematical Association of Victoria 37th Annual Conference, Melbourne, December 2000, pp 73-83

8. Shallcross D.C., 1999, 'The Mathematics of Control', Proceedings of the Mathematical Association of Victoria 36th Annual Conference, Melbourne, December 1999, pp 328-336

\section{Biographical Information}

DAVID C. SHALLCROSS is an Associate Professor in the Department of Chemical Engineering at the University of Melbourne. He is also Associate Dean of the Faculty of Engineering. He has been developing engineeringthemed exercises for the secondary school mathematics class room since 1994. He is a Councilor of the Mathematical Association of Victoria and has set assessment tasks for the Victorian Board of Studies. 